\title{
A novel approach in mucoadhesive drug delivery system to improve zidovudine intestinal permeability
}

\author{
Liliane Neves Pedreiro,"*, Beatriz Stringhetti Ferreira Cury¹, Marco Vinícius Chaud², \\ Maria Palmira Daflon Gremião ${ }^{1}$
}

\begin{abstract}
${ }^{1}$ Faculdade de Ciências Farmacêuticas, Universidade Estadual Paulista "Júlio de Mesquita Filho, UNESP, Araraquara, São Paulo, Brasil, ${ }^{2}$ Universidade de Sorocaba, Sorocaba, São Paulo, Brasil
\end{abstract}

\begin{abstract}
Zidovudine (AZT) mucoadhesive solid dispersions (SD) were prepared using a sodium starch glycolate (SSG) and hypromellose phthalate (HPMCP) mixtures as carrier to enhance the intestinal permeability and bioavailability of zidovudine. SDs were prepared using the co-precipitation method followed by solvent evaporation and characterized according to their physicochemical properties such as particle size, crystallinity, thermal behavior, and liquid uptake ability. In vitro drug dissolution, mucoadhesiveness and AZT intestinal permeability were also determined. Thermal behavior and X-ray diffraction patterns demonstrated the amorphous state of AZT in SD systems. The HPMCP polymer restricted the liquid uptake ability in the acid medium; however, this property significantly increased with higher $\mathrm{pH}$ values. SDs allowed drug dissolution to occur in a controlled manner. HPMCP decreased the dissolution rates in the acid medium. The mucoadhesiveness of SDs was demonstrated and the permeability of AZT carried in solid dispersions was significantly improved. The effect of the SD carrier polymers on blocking efflux pump can be an important approach to improve the bioavailability of AZT.
\end{abstract}

Uniterms: Zidovudine. Solid dispersion. Mucoadhesion. P-glycoprotein. Intestinal permeability.

\section{INTRODUCTION}

Initially, advances in drug delivery systems were primarily based on the synthesis of functional polymers. Currently, the development strategies of these systems are strongly influenced by a detailed understanding of the underlying biological and molecular principles. With this knowledge, more sophisticated drug delivery systems have been designed that provide better pharmacokinetics, reduced toxicity, more focused drug targeting and controlled release of the drug (Grund, Bauer, Fischer, 2011).

The development of new strategies that overcome the low bioavailability of AZT mainly focus on the efflux mechanism mediated by P-glycoprotein (P-gp), which returns drugs absorbed by the intestinal membrane back to the lumen, increasing presystemic metabolism, and these

*Correspondence: L. N. Pedreiro. Faculdade de Ciências Farmacêuticas UNESP. Rodovia Araraquara-Jaú, Km 1 - 14801902 - Araraquara - SP, Brasil. E-mail: liliane_np@yahoo.com.br / pgremiao@fcfar.unesp.br strategies must overcome the significant challenges of reducing the adverse effects that hinder patient therapeutic compliance while improving drug bioavailability (Geocze et al., 2010).

Zidovudine (Figure 1a) is the drug of choice for the treatment of Human Immunodeficiency Virus (HIV), which causes acquired immunodeficiency syndrome (AIDS). Zidovudine is a reverse transcriptase inhibitor that prevents the replication of the DNA strand from RNA through competitive inhibition of deoxynucleotide triphosphate, ultimately preventing the extension of the tape. Zidovudine needs to be converted into its triphosphate form for effective antiviral activity against the enzyme reverse transcriptase. For this to occur, zidovudine is first phosphorylated by thymidine kinase intracellularly and then transformed into diphosphate by thymidylate kinase. The triphosphate metabolite interrupts viral replication through competitive mechanisms.

Approximately $40 \%$ of the AZT dose is metabolized presystemically (Carvalho et al., 2009; Teixeira et al., 2011). Due to its low bioavailability, oral administration 
of AZT poses a major challenge to the development of new systems for controlled drug release. In addition, it is a substrate of various efflux mechanisms present in the central nervous system, immune system and intestinal epithelium, the latter being directly related to issues of drug bioavailability (Varatharajan, Thomas, 2009).

Mucoadhesive systems exploit the interaction between formulations containing polymers and the mucus layer that covers epithelial surfaces throughout the body. Due to their increased retention time and closer contact with the absorption site, mucoadhesive systems provide a promising approach for improving bioavailability by maximizing drug absorption (Carvalho et al., 2013; Ivarsson, Wahlgren, 2012; Barbi et al., 2015).

Solid dispersions (SD) are drug delivery systems in which the drugs are dispersed in an amorphous state in a hydrophilic polymer matrix. This approach has been traditionally used to improve the solubility of drugs with poor water solubility. In several drugs, it has been demonstrated that modifications of structure, solubility properties and drug release profiles can enhance bioavailability (Chen et al., 2006; Giri et al., 2012).

The SD preparation technique is a simple and low cost approach for preparing polymer matrix systems that contain drugs in an amorphous state. Studies investigating the influence of these structural changes on biological interactions, such as mucoadhesion and permeability of highly soluble drugs, have not been evaluated.

The polymer blend is a rational approach for obtaining novel materials with specific properties that allow suitable drug-release control that favors bioavailability (Carbinatto et al., 2012; Soares et al., 2013).

Sodium starch glycolate (SSG) (Figure $1 \mathrm{~b}$ ) is a polymer derived from starch largely used as a superdisintegrant in tablet formulations. It is practically insoluble in water and possesses high hydration capacity with the ability to absorb over 300 times its volume (Fransén, Björk, Edsman, 2007). The mucoadhesive properties of this polymer have been demonstrated in topical films and inhalant interactive mixtures that contain SSG (Repka, Mcginity, 2000; 2001). Furthermore, it has been reported that SSG can function as a polymeric excipient with properties that inhibit the intestinal efflux mechanisms of drugs (Takizawa et al., 2013).

Hypromellose phtalate (HPMCP) (Figure $1 \mathrm{c}$ ) is an enteric polymer largely used to coat solid dosage forms. Due to its insolubility in acid medium, HPMCP confers gastro-resistance to drugs. In addition, its hydroxyl groups interact with the mucosa via secondary non-covalent bonds and form hydrogen bonds with the mucus, resulting in its mucoadhesive properties (Makhlof, Tozuka, Takeuchi, 2011).

P-glycoprotein (P-gp) is the major efflux transporter protein present in intestinal epithelial cells, particularly in the apical membrane. It is responsible for the efflux of a wide range of structurally unrelated drugs and xenobiotics and causes drugs to flow back into the gut lumen. Studies in animals and humans have indicated that P-gp plays a major role in limiting drug absorption and consequently oral bioavailability (Bansal et al., 2009).

Thus, there is considerable interest in enhancing oral bioavailability by inhibiting P-gp-mediated drug efflux. Several studies have demonstrated that P-gp inhibitors (e.g., verapamil, VER) can improve the bioavailability of a large number of molecules (Werle, 2008; Ling et al., 2010). Takizawa et al. (2013) demonstrated the effects of 20 common pharmaceutical excipients (diluents, disintegrants, binders, lubricants and sustained release substrate) on the mucosal membrane and how their effects differ in regions of the small intestine. The effects of these excipients on the membrane permeability of 5(6)-carboxyfluorescein (5-CF) were examined using the in vitro sac method in rat jejunum and ileum. The authors found that membrane permeability of sodium carboxymethyl starch, low-substituted hydroxypropyl cellulose and croscarmellose sodium was significantly increased in the jejunum.

However, such inhibitors have intrinsic pharmacological activity and, consequently, may cause toxic side effects. Moreover, evidence suggests that excipients of pharmaceutical formulations may block intestinal P-gp function enhancing the permeability of (a) AZT

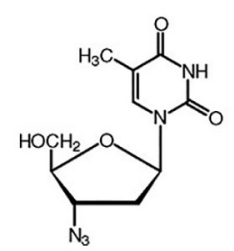

(b) SSG

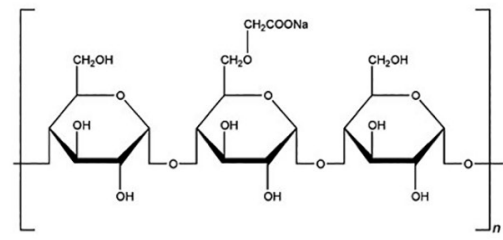

(c) HPMCP

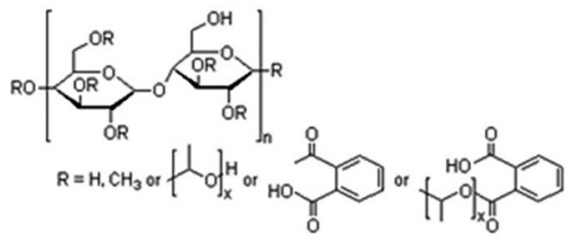

FIGURE 1 - Chemical structure of: (a) Zidovudine (AZT); (b) Sodium starch glycolate (SSG); (c) Hypromellose phthalate (HPMCP). 
the intestinal substrate drugs (Shen et al., 2006; Mudra, Borchardt, 2010).

The use of polymers for P-gp blockade has been extensively reported in the scientific literature. Studies have demonstrated that SSG and HPMCP enhance oral bioavailability through the inhibition of P-gp (CarrenoGomez, Duncan, 2001; Takizawa et al., 2013).

Despite the high solubility of AZT, the mucoadhesive SD approach could provide a simple and low cost method for preparing systems that could change the biological interaction of AZT and improve its bioavailability.

In this study, AZT SDs using SSG and HPMCP as polymer carriers were prepared and their mucoadhesiveness and intestinal permeability were evaluated. The influence of P-gp blockade on drug permeability was also investigated.

\section{MATERIAL AND METHODS}

\section{Material}

AZT was kindly provided by Fundação para o Remédio Popular - FURP, Guarulhos/SP, Brazil. Sodium starch glycolate was purchased from Henrifarma (São Paulo/SP, Brazil). Hypromellose phthalate and Verapamil were obtained from Sigma-Aldrich ${ }^{\circledR}$ (Hamburg, Germany). Other reagents were of analytical reagent grade.

\section{Solid dispersions preparation}

SDs containing AZT were prepared using coprecipitation methods followed by solvent evaporation. Varying concentrations of SSG and HPMCP $(1: 10: 10$ and 1:15:15; AZT: SSG: HPMCP) were used as carrier polymers. AZT and SSG were dissolved in a sufficient amount of ethanol, under magnetic stirring (30 min). HPMCP previously dissolved in $\mathrm{NaOH}$ solution $(0.05 \mathrm{M})$ was added to the ethanol solution containing AZT and SSG. The mixture was stirred for 15 min. Afterwards, the solvent was evaporated using a rotary evaporator (Tecnal ${ }^{\circledR}$, Ourinhos/SP, Brazil) under reduced pressure at $45^{\circ} \mathrm{C}$ for $3 \mathrm{~h}$. The samples were dried in an oven-drier at $60^{\circ} \mathrm{C}$ (Marconi MA $035^{\circledR}$, Piracicaba/SP - Brazil) until the moisture content of the samples was less than $10 \%$. The product was manually milled using a mortar. The particles were sieved $(0.42 \mathrm{~mm})$ and stored in a desiccator. Physical mixtures (PM) using the same drug:polymer ratios were prepared as the control.

\section{Fourier transform infrared spectroscopy (FTIR)}

FTIR spectra were recorded in the $4000-400 \mathrm{~cm}^{-1}$ range using an FT-IR spectrometer (Shimadzu ${ }^{\circledR} 8300$, Kyoto - Japan). The samples were analyzed using $\mathrm{KBr}$ pellets. The powders were compressed at a pressure of 8 tons for 3 min using a hydraulic press (Shimadzu ${ }^{\circledR}$ SSP10A, Kyoto - Japan).

\section{Differential scanning calorimetry (DSC)}

Thermal analyses were carried out using a DSC unit (DSC 1 Stare System, Mettler Toledo ${ }^{\circledR}$, Zurich, Switzerland). Indium and zinc were used to calibrate the temperature scale and enthalpic response. Samples (5 $\mathrm{mg}$ ) were placed in aluminum pans before heating under nitrogen flow $(50 \mathrm{~mL} / \mathrm{min})$ at a scanning rate of $10^{\circ} \mathrm{C} / \mathrm{min}$ from 25 to $200^{\circ} \mathrm{C}$. An empty aluminum pan was used as the reference.

\section{X-ray diffraction (DRX)}

$\mathrm{X}$-ray powder diffraction was performed at room temperature with an X-ray diffractometer (Siemens ${ }^{\circledR}$ D5000, Berlin, Germany) using monochromatic $\mathrm{Cu}-\mathrm{K} \alpha$ radiation $(\lambda=1.5406 \AA)$ operating at $40 \mathrm{kV}$ and $30 \mathrm{~mA}$. Samples were analyzed in the range of $2-60^{\circ}(2 \theta)$ using a step size of $0.02^{\circ}(2 \theta)$ and scan step time of $0.05 / \mathrm{min}$.

\section{Liquid uptake ability}

The liquid uptake ability was assessed using an Enslin device (Cury et al., 2009; Prezotti et al., 2012). An accurately weighted mass of SD (0.05 g) was uniformly spread on a sintered glass filter. The volume of medium absorbed by the samples was measured using a pipette at predetermined times $(5,30,60,90$ and $120 \mathrm{~min})$. Two different media were tested: simulated gastric medium $(0.1 \mathrm{~N} \mathrm{HCl}, \mathrm{pH} 1.2)$ and simulated enteric medium (phosphate buffer, $\mathrm{pH}$ 7.4). Neither of the media contained enzymes. The tests were performed in triplicate and expressed as the percentage of liquid uptake relative to the initial mass of the samples, according to equation (Eq. 1):

$$
\% S=\frac{V}{m}
$$

where $m$ is the initial mass of $\mathrm{SD}(\mathrm{g}) ; V=$ volume $(\mathrm{mL})$ of medium uptake, $\% S=$ percentage of media uptake of the samples.

\section{In vitro adhesion test}

Mucoadhesion properties were evaluated using a texture analyzer (TA.XT plus, Stable Micro Systems, 
Godalming, UK) with $50 \mathrm{~N}$ load cell, according to the procedure described by Fransén, Björk and Edsman (2007). Mucin discs (11 mm diameter) were pre-hydrated in simulated enteric medium (phosphate buffer, $\mathrm{pH}$ 7.4) at $37^{\circ} \mathrm{C}$ for 60 seconds. Immediately after, the discs were attached to a metallic sample holder using double-sided adhesive tape.

The cylindrical ended probe ( $10 \mathrm{~mm}$ diameter) was covered with double-sided adhesive tape containing the sample. For this step, the adhesive tape was carefully pressed against a flat surface containing the powdered sample to create a monolayer of particles. The probe was moved downward with a speed of $2.0 \mathrm{~mm} / \mathrm{s}$, until contact was made with the mucin disc; contact was maintained for 600 seconds. Afterwards, the probe was raised at $2.0 \mathrm{~mm} / \mathrm{s}$. The maximum force required to detach the probe from the sample could be detected directly using Texture Exponent Lite software. The total amount of force involved in probe withdrawal (Wad $-\mu \mathrm{J})$ was determined by calculating the area under the force versus distance curve. The tests were repeated six times in compression test mode with $2 \mathrm{mN}$ of triggered force.

\section{In vitro drug release}

In vitro drug release tests were performed using a Hanson Dissolution Test Station SR8-Plus (Chatsworth - USA) equipped with $150 \mathrm{~mL}$ vessels and mini paddles, based on the design of apparatus 2 (USP), to mimic system hydrodynamics. In vitro drug release was performed in simulated gastric medium $(0.1 \mathrm{~N} \mathrm{HCl}, \mathrm{pH} 1.2)$ for $2 \mathrm{~h}$ and in simulated enteric medium (phosphate buffer $\mathrm{pH}$ 7.4) for $4 \mathrm{~h}$. The media were kept at $37^{\circ} \mathrm{C}$, while stirring at $50 \mathrm{rpm}$. AZT-free powder served as the control and was also tested.

All samples were put into hard gelatin capsules (size 0 ). The amount of AZT released was quantified at predetermined times using a UV spectrophotometer (Hewlett Packard 8453, California - USA) with an absorption of $267 \mathrm{~nm}$. These tests were performed in triplicate under sink conditions.

\section{Intestinal permeability and P-glycoprotein influence}

The intestinal permeability of AZT was evaluated using the everted gut sac model described by Barthe et al. (1998a) with modifications purposed by Quevedo et al. (2011). The animals were handled in accordance with the guide for the care and use of experimental animals (CEUA/ UFSCAR Ethics in Research Committee, $n^{\circ}$ 003/2011).

Male adult Wistar rats (250-270 g) were kept under fasting conditions for $12 \mathrm{~h}$ before the assay and then anesthetized with sodium thiopental. Immediately after, a duodenum segment (approximately $6 \mathrm{~cm}$ length) was dissected, flushed with TC 199 buffer solution (culture medium) at $10{ }^{\circ} \mathrm{C}$ and placed in oxygenated $\left(\mathrm{O}_{2}: \mathrm{CO}_{2}-\right.$ 95:5) TC 199 buffer of the same temperature. This segment was gently inverted with the aid of a flexible cotton swab (mini brush, $\sim 2.5 \mathrm{~mm}$ diameter). The intestinal segment was filled with fresh TC 199 medium and its ends were clamped to make a closed sac. The everted sac was incubated at $37^{\circ} \mathrm{C}$ in $20 \mathrm{ml}$ of TC 199 with 10 $\mathrm{mM}$ oxygenated $\left(\mathrm{O}_{2}: \mathrm{CO}_{2}-95: 5\right)$ glucose containing 600 $\mu \mathrm{g} / \mathrm{mL}$ of sample (AZT free powder, SD 1:15:15 or PM $1: 15: 15)$. The assay time was standardized in 90 minutes to maintain the viability of the intestinal tissue (Barthe et al., 1998b; Barthe, Woodley, Houin, 1999). Afterwards, the everted sacs were removed from the incubation medium, externally washed with fresh TC 199 and cut to obtain the internal content. The content was filtered through a cellulose membrane filter (MilliPore $0.45 \mathrm{~mm}$ ) and analyzed using the Varian ProStar ${ }^{\circledR}$ HPLC 330 UVVIS PDA spectrophotometric detector and Rheodine VS 125 (SpectraLab, Toronto - Canada) (Carvalho et al., 2009). The buffer solution (TC-199, pH 7.4) used in all preparations was freshly prepared and had a composition of $145 \mathrm{mM} \mathrm{NaCl}, 4.56 \mathrm{mM} \mathrm{KCl}, 1.25 \mathrm{mM} \mathrm{CaCl} 2,5 \mathrm{mM}$ NaHPO4 and $10 \mathrm{mM}$ glucose (Correa et al., 2011).

To evaluate the influence of P-gp on AZT permeability, the same assay described above was performed with the addition of $50 \mu \mathrm{g} / \mathrm{mL}$ of VER added to the medium (Quevedo et al., 2011). The tests were replicated six times.

\section{Statistical analysis}

One-way ANOVA followed by Tukey's multiple comparison procedure was used for statistical analysis of the data. A $p$ value less than 0.05 was considered statistically significant.

\section{RESULTS AND DISCUSSION}

The AZT IR spectrum (Figure 2a) showed three characteristic peaks related to the stretching bands of the $\mathrm{OH}$ group, the $\mathrm{C}-\mathrm{O}$ of $\mathrm{OH}$ groups and $\mathrm{C}=\mathrm{N}=\mathrm{N}=\mathrm{N}$ (azide group) at 3550-3200 $\mathrm{cm}^{-1}, 1089 \mathrm{~cm}^{-1}$ and 2083 $\mathrm{cm}^{-1}$, respectively (Araújo et al., 2003). In the SSG IR spectrum (Figure $2 \mathrm{~b}$ ) peaks assigned to $\mathrm{C}=\mathrm{C}$ of the $\mathrm{CH}_{2}$ group appeared approximately $1640 \mathrm{~cm}^{-1}$ while $\mathrm{OH}$ stretching bands were observed in the $3550-3200 \mathrm{~cm}^{-1}$ range. $\mathrm{C}-\mathrm{O}$ of the ether group was observed in the 1275 
at $1020 \mathrm{~cm}^{-1}$ range (Puttipipatkhachorn, Pongjanyakul, Priprem, 2005). The HPMCP IR spectrum (Figure $2 \mathrm{c}$ ) revealed absorption bands between 3500 and $3200 \mathrm{~cm}^{-1}$ reflecting $\mathrm{O}-\mathrm{H}$ stretching while the peaks related to $\mathrm{CH}$ $\left(\mathrm{sp}^{3}\right)$ and $\mathrm{C}=\mathrm{O}$ of the ester group were observed at 2800 $\mathrm{cm}^{-1}$ and $1700 \mathrm{~cm}^{-1}$, respectively. The band at 1600 to $1550 \mathrm{~cm}^{-1}$ was assigned to an aromatic ring and 1000 to $1200 \mathrm{~cm}^{-1}$ bands were assigned to ether. A peak at 740 $\mathrm{cm}^{-1}$ was attributed to a monosubstituted aromatic ring (Miyazaki et al., 2011). FTIR spectrum analyses were performed to identify the characteristic functional groups of the polymers and drug. FTIR spectrum analysis was also used to evaluate possible interactions between the drug and polymer in the SD samples. The characteristic peaks of the drug and isolated polymers were recorded. The SD and PM IR spectra were similar to those of AZT, SSG and HPMCP. The peaks indicated that there were no chemical interactions, only physical interactions between the components of the system (Araújo et al., 2003).

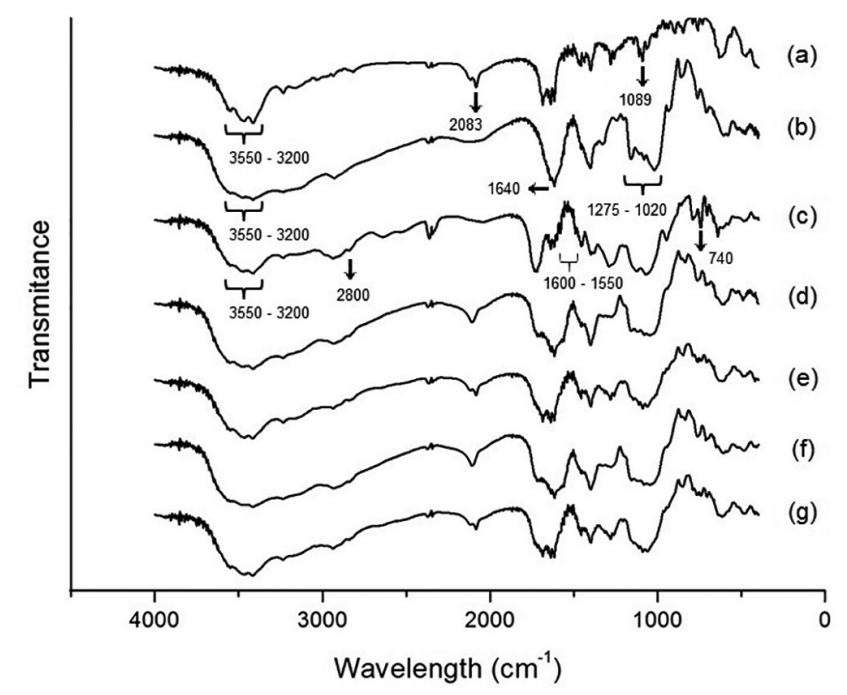

FIGURE 2 - FT-IR spectra of (a) AZT; (b) SSG; (c) HPMCP; (d) SD 1:10:10; (e) PM 1:10:10; (f) SD 1:15:15; (g) PM 1:15:15.

The DSC data of AZT, SSG, HPMCP, SDs and PMs are shown in Figure 3. The AZT thermogram revealed an endothermic peak at $126.7^{\circ} \mathrm{C}$, which was related to drug melting (Maru et al., 2011), while the SSG and HPMCP exhibited a broad endothermic peak in the thermograms due to its amorphous nature (Puttipipatkhachorn et al., 2005). The occurrence of these events is attributed to a significant amount of drug in its crystalline state (Cides et al., 2006). The absence of any peculiar endothermic peaks in the SD thermograms suggests that AZT was predominantly in the amorphous form. In addition, the absence of these peaks has been attributed to the formation of solid drug solution within the polymer matrix (Soares et al., 2013).

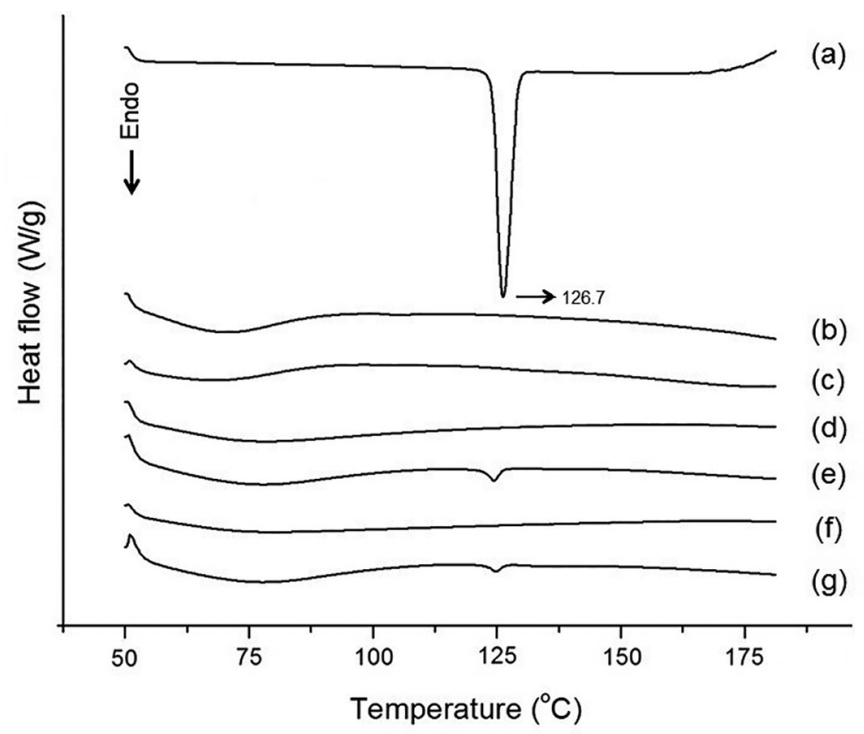

FIGURE 3 - DSC of (a) AZT; (b) SSG; (c) HPMCP; (d) SD 1:10:10; (e) PM 1:10:10; (f) SD 1:15:15; (g) PM 1:15:15.

The diffractograms of AZT, SSG, HPMCP, SDs and PMs are shown in Figure 4. AZT diffractograms present characteristic peaks approximately 21, 22, 24, 26, 30 and $32(2 \theta)$. The diffraction patterns exhibited by the SDs and PMs were similar to the peaks isolated in the polymers (SSG and HPMCP). The SD and PM diffractograms were an addition of both isolated polymers (SSG and HPMCP). The absence of drug-associated peaks in SDs, a result of crystalline structure disruption, is consistent with

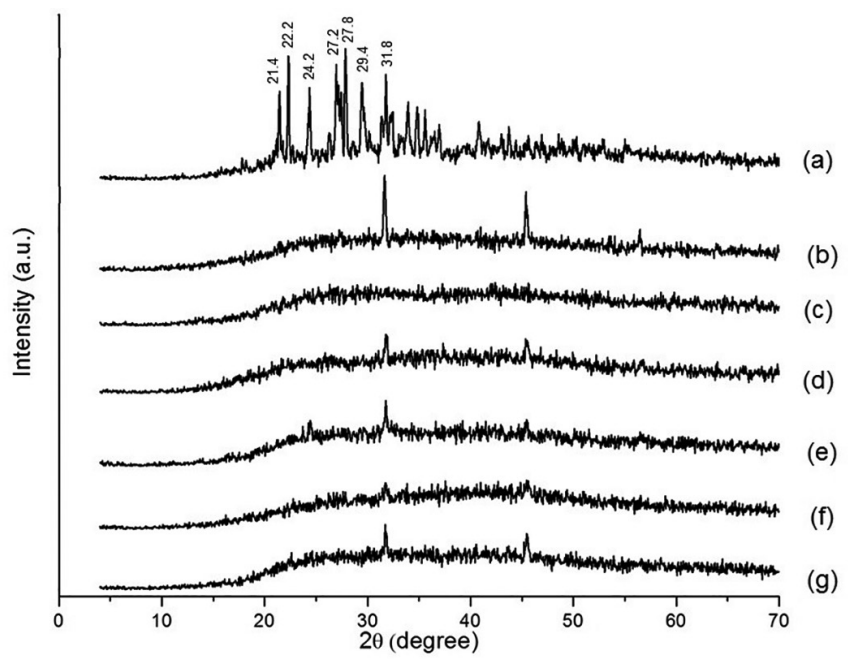

FIGURE 4 - X-ray diffraction patterns of (a) AZT; (b) SSG; (c) HPMCP; (d) SD 1:10:10; (e) PM 1:10:10; (f) SD 1:15:15; (g) PM 1:15:15. 
the amorphous state of the drug in the solid dispersions revealed by the DSC analysis. In PMs, this absence can be the result of dilution due to the high proportion of polymers in the matrix.

The liquid uptake values (\%) of SD, SSG and HPMCP in simulated gastric medium are shown in Table I. The SSG had the highest values (560.34\%) and reached equilibrium in a short time $(5 \mathrm{~min})$. The $\% \mathrm{~S}$ values of SD 1:10:10 and SD 1:15:15 were $395.31 \%$ and $409.79 \%$, respectively. The liquid uptake ability in simulated enteric medium showed that all samples (except HPMCP) exhibited significantly higher $\% \mathrm{~S}$ values $(\mathrm{p}<0.05)$ than those in simulated gastric medium. In addition, SD 1:15:15 exhibited the highest $\% \mathrm{~S}$ value (2074.44) followed by SD 1:10:10, SSG and HPMCP, in that order. Polymeric swelling is an important property of the mucoadhesion process because it contributes to the mobility and expansion of polymer chains. Both of these factors allow for polymer interpenetration with mucin. Liquid absorption is the first step in the relaxation and expansion of polymer chains that characterize swelling behavior. The high swelling values of SSG in both media can be attributed to the peculiar behavior of swellable superdisintegrant polymers, such as SSG, because their action mechanism is based on the rapid expansion of the polymer matrix after contact with the aqueous environment. This behavior causes the development of tension in delimited regions that causes the structure to break into small particles (Bele, Derle, 2012).

The $\%$ S values of SD 1:10:10 and SD 1:15:15 demonstrated that the polymer concentration did not affect the liquid sorption ability of SDs ( $p>0.05$ ), while HPMCP can restrict it in acid medium due to its insolubility when the $\mathrm{pH}$ is low. Increased liquid uptake values in the simulated enteric medium indicated that increases in $\mathrm{pH}$ should favor carboxyl group repulsion in HPMCP, causing the chains to move farther apart loosening the polymer matrix. Both of these factors favor the entrance of water molecules (Oliveira et al., 2010).

According to Table II, the highest $\mathrm{W}_{\mathrm{ad}}$ value was exhibited by HPMCP while SSG and SD $\mathrm{W}_{\text {ad }}$ values were similar $(\mathrm{p}>0.05)$. Despite the high $\mathrm{W}_{\mathrm{ad}}$ values of HPMCP, its presence did not affect the adhesiveness of SD because the $W_{\text {ad }}$ values of SD 1:10:10 and 1:15:15 were similar to SSG $(p>0.05)$. This indicated that this polymer determined this property of solid dispersions. The adhesiveness of polymeric systems is a very important property contributing to increased retention time and closer contact with mucous. These factors improve the permeability and bioavailability of drugs with typically poor bioavailability, such as AZT. The high adhesiveness of HPMCP (Table II) may be a result of interactions between the hydroxyl groups and mucin via noncovalent secondary connections that build the hydrogen bonds. In addition, HPMCP is a swellable bioadhesive polymer derived from cellulose. Swelling enhances the adhesiveness of HPMCP through the interpenetration of the swollen polymer flexible chains in mucin (Andrews, Laverty, Jones, 2009). However, the $\mathrm{W}_{\mathrm{ad}}$ values of the SD samples examined in this study were similar to those of well-known adhesive polymers, such as carbopol 971P, polycarbophil AA1, sodium carboxymethylcellulose and carrageenan (Eouani et al., 2001), verifying their significant mucoadhesive properties. Despite the higher liquid sorption ability of SD in enteric medium when compared to HPMCP, the mucoadhesiveness of SD was

TABLE I - Liquid uptake ability (\%) of samples

\begin{tabular}{lcccccccc}
\hline \multirow{2}{*}{$\begin{array}{l}\text { Time } \\
(\text { min) }\end{array}$} & \multicolumn{7}{c}{ SSG } & \multicolumn{7}{c}{ LPMCP } & \multicolumn{2}{c}{ SD 1:10:10 } & \multicolumn{2}{c}{ SD 1:15:15 } \\
\cline { 2 - 9 } & $\boldsymbol{a}$ & $\boldsymbol{b}$ & $\boldsymbol{a}$ & $\boldsymbol{b}$ & $\boldsymbol{a}$ & $\boldsymbol{b}$ & $\boldsymbol{a}$ & $\boldsymbol{b}$ \\
\hline 5 & 511.08 & 869.29 & 208.59 & 221.40 & 247.07 & 793.17 & 287.46 & 1015.23 \\
& $( \pm 76.90)$ & $( \pm 10.83)$ & $( \pm 21.25)$ & $( \pm 18.45)$ & $( \pm 38.57)$ & $( \pm 211.35)$ & $( \pm 21.18)$ & $( \pm 109.90)$ \\
30 & 529.56 & 875.55 & 214.72 & 258.30 & 284.13 & 1159.24 & 311.93 & 1269.04 \\
& $( \pm 76.90)$ & $( \pm 21.66)$ & $( \pm 38.31)$ & $( \pm 18.45)$ & $( \pm 53.49)$ & $( \pm 211.35)$ & $( \pm 18.34)$ & $( \pm 109.90)$ \\
60 & 541.87 & 894.31 & 220.86 & 270.60 & 339.72 & 1464.31 & 348.62 & 1649.75 \\
& $( \pm 74.65)$ & $( \pm 21.66)$ & $( \pm 31.87)$ & $( \pm 21.30)$ & $( \pm 10.69)$ & $( \pm 317.03)$ & $( \pm 18.34)$ & $( \pm 109.90)$ \\
90 & 554.19 & 919.32 & 220.86 & 295.20 & 376.78 & 1830.38 & 385.32 & 2030.46 \\
& $( \pm 84.65)$ & $( \pm 18.76)$ & $( \pm 31.87)$ & $( \pm 18.45)$ & $( \pm 10.69)$ & $( \pm 317.03)$ & $( \pm 18.34)$ & $( \pm 109.90)$ \\
120 & 560.34 & 938.09 & 220.86 & 313.65 & 395.31 & 2074.44 & 409.79 & 2284.26 \\
& $( \pm 92.97)$ & $( \pm 18.76)$ & $( \pm 31.87)$ & $( \pm 18.45)$ & $( \pm 10.69)$ & $( \pm 211.35)$ & $( \pm 10.59)$ & $( \pm 190.35)$ \\
\hline
\end{tabular}

(a) simulated acid medium $0.1 \mathrm{~N} \mathrm{HCl}(\mathrm{pH} 1.2) ;(b)$ simulated phosphate buffer ( $\mathrm{pH} 7.4)$. 
lower than HPMCP. These results are consistent with findings regarding other crucial properties of adhesiveness in SD samples. In this sense, the SSG molecular weight could have contributed to steric hindrance that harmed the ability of swollen polymer flexible chains to interpenetrate into the mucin meshes of mucus, limiting the adhesiveness of SD samples (Lai, Wang, Hanes, 2009).

TABLE II - Mucoadhesive performance of polymers and SDs

\begin{tabular}{lc}
\hline SAMPLE & $\mathbf{W}_{\text {ad }}(\mu \mathbf{J})$ \\
\hline SSG & $1896( \pm 0.69)$ \\
HPMCP & $3137( \pm 0.51)$ \\
SD 1:10:10 & $1507( \pm 0.25)$ \\
SD 1:15:15 & $1702( \pm 0.29)$ \\
\hline
\end{tabular}

In acid medium, the AZT-free drug release profile (Figure 5) showed that approximately $50 \%$ of the drug was released in 15 minutes. On the other hand, SD 1:10:10 and SD 1:15:15 released only 11\% $( \pm 0.0178)$ and $19 \%$ $( \pm 0.0100)$ of the drug in 15 minutes, and $19 \%( \pm 0.0012)$ and $37 \%( \pm 0.0184)$ in 30 minutes, respectively. In enteric medium, the drug release profiles demonstrated that SD 1:10:10 was also able to release $81 \%( \pm 0.0716)$ of the drug at 60 minutes and SD 1:15:15 was able to release $80 \%( \pm 0.1097)$ in 90 minutes. The AZT-free drug release profile reached $80 \%$ in 45 minutes in acid medium (Figure 5) because it is highly soluble in this medium. SD 1:10:10 and SD 1:15:15 exhibited low drug release rates in acid media releasing 19\% $( \pm 0.0012)$ and $37 \%( \pm 0.0184)$ of drug, respectively in $30 \mathrm{~min}$. This behavior can be attributed to the gastro-resistance properties of HPMCP, which exhibited lower swelling in this medium (Table 1), avoiding erosion and contributing to decreasing drug release rates (Oliveira et al., 2010). Indeed, it can be observed despite the presence of HPMCP, an enteric polymer, the drug release rates in the first 15 minutes were very similar for both acid and enteric media. However, after 30 minutes, the drug release rates were higher in enteric than in acid medium, suggesting HPMCP dissolution. HPMCP dissolution increases the drug dissolution rate.

HPMCP is used in SDs to control drug release rates due to its insolubility in gastric fluid and its capacity to dissolve in the upper intestine at $\mathrm{pH}$ values higher than 5.5 (Giri et al., 2012). The association of HPMCP with SSG, a polymer that quickly swells in aqueous medium, allows a swollen matrix to form that entraps the drug decreasing the drug release rate. The $\mathrm{pH}$-dependence of HPMCP leads to polymeric hydration in the enteric medium, enabling the formation of water-filled pathways by which AZT can be released (Kim et al., 2007).

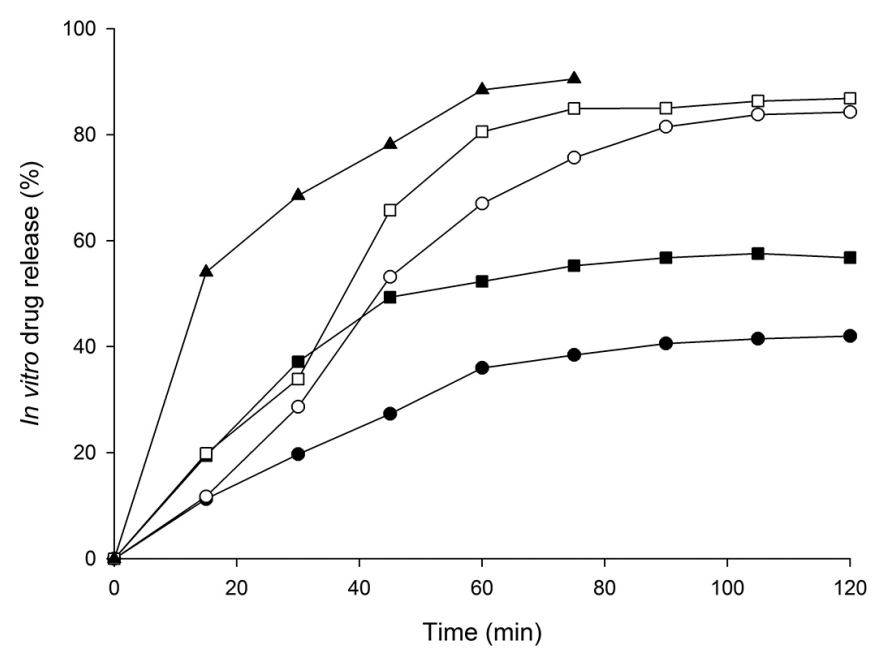

FIGURE 5 - AZT release profiles from SD: $(\boldsymbol{\Delta})$ AZT; $(\bullet)$ SD 1:10:10, (ロ) SD 1:15:15 in simulated gastric medium; (०) SD 1:10:10, (口) SD 1:15:15 in simulated enteric medium.

The intestinal permeability of free AZT, SD and PM (shown in Figure 6), was significantly higher in SD $(65.2 \%)$ than in free AZT $(33.9 \%)(\mathrm{p}<0.05)$. The drug permeability was reduced in PM (45.5\%); however, the permeability of PM did not differ significantly from other samples ( $p>0.05)$. The presence of VER, a P-gp blocker, improved the permeability of the free drug $(43.5 \%)(p<0.05 \%)$; however, it did not influence SD drug permeability $(69.7 \%, \mathrm{p}>0.05 \%)$. In Figure 6 , it is clear that the permeability of AZT carried in SD was significantly greater $(69.6 \%)$ when compared to free AZT (33.9\%) and PM (45.4\%). This sharp increase in permeability of AZT carried in SD may be a result of the formation of a solid amorphous drug solution in the polymer matrix that modified the biological interaction improving its permeability.

The permeation values of PM (45.4\%) were similar to those observed in free AZT in the presence of VER (43.5\%). The presence of VER did not affect the permeation of $\mathrm{SD}(\mathrm{p}>0.05)$. VER is a known P-gp inhibitor that blocks the efflux pump and improves AZT permeation (Quevedo et al., 2011). These findings alerted us to the similarities between the P-pg blocking effects of VER and carrier polymers.

The similarity difference between drug permeability from SD and PM (Figure 6) indicated that the drug amorphization (Figure 3) inherent to SD preparation did not affect this property. Based on this finding, carrier polymers are imperative for increasing permeability for 


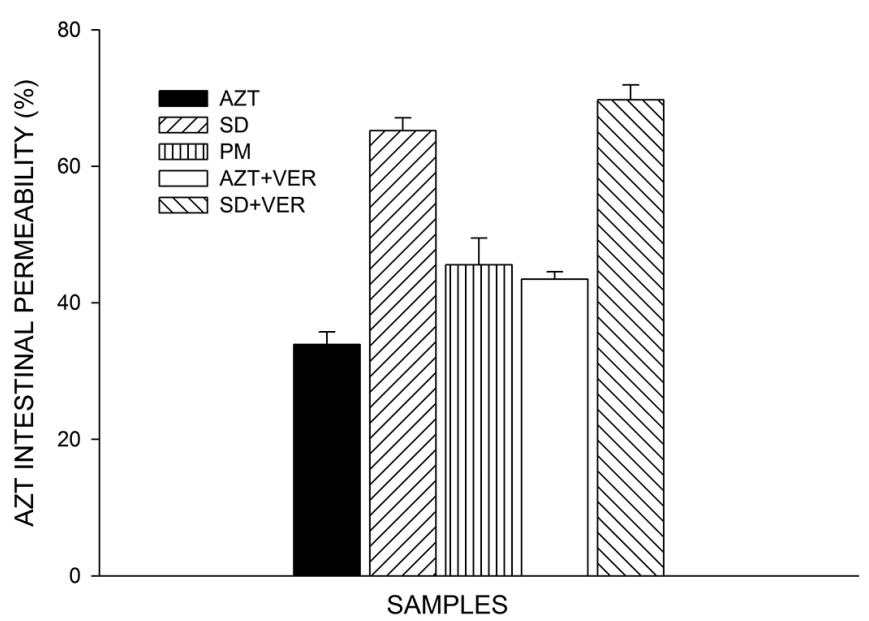

FIGURE 6 - Intestinal permeability of AZT by everted intestinal sac.

the following reasons. First, the high liquid absorption ability of SD should allow a high degree of swelling in polymers, particularly of SSG, contributing to the mucoadhesion of the system. Closer contact between the drug and epithelium and a high local concentration gradient enhances AZT permeability. In addition, the high hydration capacity of polymers can lead to the accumulation of liquid around the intestinal membrane. This accumulation results in high hydrostatic pressure in the paracellular junctions, promoting their opening. Thus, the passage of drug through the intestinal membrane is favored and drug permeation is increased.

The influence of P-gp on AZT permeation was examined by examining the permeability of free AZT in the presence of VER, a known P-gp inhibitor. Addition of VER improved AZT permeation; however, the same trend was not observed in the SD samples, which were unaffected by VER ( $p>0.05)$. These findings pointed to the possibility that carrier polymers and VER exert similar influences by inhibiting the efflux pump via P-gp inhibition thereby improving AZT permeation.

In a recent study, Takizawa et al. (2013) investigated the influence of pharmaceutical excipients, such as microcrystalline cellulose (MCC), starch sodium glycolate (SSG), hydroxypropylmethyl cellulose (HPMC), ethyl cellulose (EC), and others on the membrane permeation of 5(6)-carboxyfluorescein (5-CF) in rat jejunum and ileum using the in vitro sac method. SSG significantly increased the membrane permeability of 5-CF in the jejunum, demonstrating that this polymer influences the intestinal efflux pump mechanism and enhances drug permeation. However, the membrane permeationenhancing mechanism has not yet been elucidated. Complementary studies will be necessary to determine the effects of pharmaceutical excipients on drug transport via paracellular and transcellular mechanisms and membrane transporters.

This interesting efflux pump inhibitor effect has also been reported in studies of several polymers, including Pluronic P85, Myrj 52 and chitosan-4-thiobutylamidine, polyethylene glycols, amphiphilic block copolymers, dendrimers, thiolated polymers, and dextran sulphatePLGA hybrid (Werle, 2008; Ling et al., 2010).

Jodoin, Demeule, Béliveau (2002) and Honda et al. (2004) also demonstrated that polyphenols of green tea and compounds of grapefruit juice represent natural polymeric efflux pump inhibitors. Carreno-Gomez and Duncan (2001) have patented the use of polysaccharides, dendrimers and surfactants as efflux pump inhibitors for the oral delivery of several drugs with low absorption. It has been revealed with experimental data that anionic gums (polysaccharides), dextran and sodium alginates possess the ability to inhibit efflux pumps.

According to the permeability data, the effects of SD carrier polymers on efflux pumps can be an additional important approach to be further exploited to improve the bioavailability of AZT.

\section{CONCLUSION}

DSC and XRD data demonstrated the amorphous state of drugs in SD and the lack of chemical interaction between drugs and carriers. The liquid uptake ability was sensitive to $\mathrm{pH}$ and was limited in acid medium because of HPMCP. The high adhesiveness of SDs was demonstrated, and steric hindrance seems to be a key factor in this process. The dissolution rates in acid medium were decreased probably due to the properties of HPMCP. Increases in polymer concentration contributed to the control of drug release rates. The intestinal permeability of AZT carried in SD was enhanced. The results indicated that the roles of polymer carriers and P-gp blockers are similar, improving this property. This study provides valuable insights for future experiments and provides a promising tool to increase the bioavailability of drugs.

\section{ACKNOWLEDGEMENTS}

The authors are grateful to Fundação para o Remédio Popular (FURP), Brazil, for the donation of AZT and gratefully acknowledge the financial support provided by the Fundação de Amparo à Pesquisa do Estado de São Paulo (FAPESP) and the Coordenação de Aperfeiçoamento de Pessoal de Nível Superior (Capes). We would also like to thank Fabíola Garavello Prezotti. 


\section{REFERENCES}

ANDREWS, G.P.; LAVERTY, T.P.; JONES, D.S. Mucoadhesive polymeric platforms for controlled drug delivery. Eur. $J$. Pharm. Biopharm., v.71, n.3, p.505-518, 2009.

ARAÚJO, A.A.S.; STORPIRTIS, S.; MERCURI, L.P.; CARVALHO, F.M.S.; SANTOS FILHO, M.D.; MATOS, J.R. Thermal analysis of the antiretroviral zidovudine (AZT) and evaluation of the compatibility with excipients used in solid dosage forms. Int. J. Pharm., v.260, n.2, p.303-314, 2003.

BANSAL, T.; MISHRA, G.; JAGGI, M.; KHAR, R.K.; TALEGAONKAR, S. Effect of P-glycoprotein inhibitor, verapamil, on oral bioavailability and pharmacokinetics of irinotecan in rats. Eur. J. Pharm. Sci., v.36, n.4-5, p.580590, 2009.

BARBI, M.D.S.; CARVALHO, F.C.; KIILL, C.P.; DA SILVA, H.B.; SANTAGNELI, S.H.; RIBEIRO, S.J.L.; GREMIÃO, M.P.D. Preparation and Characterization of Chitosan Nanoparticles for Zidovudine Nasal Delivery. J. Nanosci. Nanotechnol., v.15, n.1, p.865-874, 2015.

BARTHE, L.; BESSOUET, M.; WOODLEY, J.F.; HOUIN, G. The improved everted gut sac: a simple method to study intestinal P-glycoprotein. Int. J. Pharm., v.173, n.1-2, p.255-258, 1998a.

BARTHE, L.; WOODLEY, J.; HOUIN, G. Gastrointestinal absorption of drugs: methods and studies. Fundam. Clin. Pharmacol., v.13, n.2, p.154-168, 1999.

BARTHE, L.; WOODLEY, J.F.; KENWORTHY, S.; HOUIN, G. An improved everted gut sac as a simple and accurate technique to measure paracellular transport across the small intestine. Eur. J. Drug Metab. Pharmacok., v.23, n.2, p.313-23, 1998b.

BELE, M.H.; DERLE, D.V. Mechanism of disintegrant action of polacrilin potassium: Swelling or wicking? Acta Pharm. Sinica, v.2, n.1, p.70-76, 2012.

CARBINATTO, F.M.; DE CASTRO, A.D.; CURY, B.S.F.; MAGAlHÃES, A.; EVANGELISTA, R.C. Physical properties of pectin - high amylose starch mixtures crosslinked with sodium trimetaphosphate. Int. J. Pharm., v.423, n.2, p.281-288, 2012.
CARRENO-GOMEZ, B.; DUNCAN, R. Compositions with enhanced oral bioavailability. $\mathrm{N}^{\circ} \mathrm{WO} / 2001 / 052896, \mathrm{PCT} /$ EP2001/000415, 2001.

CARVALHO, F.; BARBI, M.D.S.; GREMIÃO, M.LC. Evaluation of in vitro release of AZT from microemulsions. Chromatography., v.69, p.207-211, 2009.

CARVALHO, F.C.; CAMPOS, M.L.; PECCININI, R.G.; GREMIAO, M.P. Nasal administration of liquid crystal precursor mucoadhesive vehicle as an alternative antiretroviral therapy. Eur. J. Pharm. Biopharm., v.84, n.1, p.219-227, 2013.

CHEN, R.; TAKAHASHI, H.; OKAMOTO, H.; DANJO, K. Particle design of three-component system for sustained release using a 4-fluid nozzle spray-drying technique. Chem. Pharm. Bull., v.54, n.11, p.1486-1490, 2006.

CIDES, L.; ARAÚJO, A.; SANTOS-FILHO, M.; MATOS, J. Thermal behaviour, compatibility study and decomposition kinetics of glimepiride under isothermal and non-isothermal conditions. J. Therm. Anal. Calorim., v.84, n.2, p.441-445, 2006.

CORREA, E.M.; VILA, M.M.; JUNIOR, J.M.; ZAPAROLI, R.E.; GRANATO, M.M.; GOES, A.L.; MORAES, L.C.; PAULA, F.C.; CHAUD, M.V. Assessment of solubility and intestinal absorption in vitro of praziquantel in solid dispersions of polyethylene glycol 6000. Lat. Am. J. Pharm., v.30, n.10, p.1910, 2011.

CURY, B.S.F.; CASTRO, A.D.; KLEIN, S.I.; EVANGELISTA, R.C. Modeling a system of phosphated cross-linked high amylose for controlled drug release. Part 2: Physical parameters, cross-linking degrees and drug delivery relationships. Int. J. Pharm., v.371, n.1-2, p.8-15, 2009.

EOUANI, C.; PICCERELLE, P.; PRINDERRE, P.; BOURRET, E.; JOACHIM, J. In-vitro comparative study of buccal mucoadhesive performance of different polymeric films. Eur. J. Pharm. Biopharm., v.52, n.1, p.45-55, 2001.

FRANSÉN, N.; BJÖRK, E.; EDSMAN, K. Changes in the mucoadhesion of powder formulations after drug application investigated with a simplified method. J. Pharm. Sci., v.97, n.9, p.10, 2007. 
GEOCZE, L.; MUCCI, S.; DE MARCO, M.A.; NOGUEIRAMARTINS, L.A.; CITERO, V.D.A. Qualidade de vida e adesão ao tratamento anti-retroviral de pacientes portadores de HIV. Rev. Saúde Públ., v.44, p.743-749, 2010.

GIRI, T.K.; KUMAR, K.; ALEXANDER, A.; AJAZUDDIN; BADWAIK, H.; TRIPATHI, D.K. A novel and alternative approach to controlled release drug delivery system based on solid dispersion technique. Bull. Fac. Pharm. Cairo Univ., v.50, n.2, p.147-159, 2012.

GRUND, S.; BAUER, M.; FISCHER, D. Polymers in drug delivery - state of the art and future trends. Adv. Eng. Mat., v.13, n.3, p.B61-B87, 2011.

HONDA, Y.; USHIGOME, F.; KOYABU, N.; MORIMOTO, S.; SHOYAMA, Y.; UCHIUMI, T.; KUWANO, M.; OHTANI, H.; SAWADA, Y. Effects of grapefruit juice and orange juice components on P-glycoprotein- and MRP2-mediated drug efflux. Br. J. Pharm., v.143, n.7, p.856-864, 2004.

IVARSSON, D.; WAHLGREN, M. Comparison of in vitro methods of measuring mucoadhesion: Ellipsometry, tensile strength and rheological measurements. Coll. Surf. B., v.92, p.353-359, 2012.

JODOIN, J.; DEMEULE, M.; BÉLIVEAU, R. Inhibition of the multidrug resistance $\mathrm{P}$-glycoprotein activity by green tea polyphenols. BBA - Mol. Cel. Res., v.1542, n.1-3, p.149$159,2002$.

KIM, M.-S.; KIM, J.-S.; KANG, S.-H.; YOO, Y.-H.; LEE, S.; PARK, J.-S.; WOO, J.-S.; HWANG, S.-J. Influence of water soluble additives and HPMCP on drug release from sureleaseê-coated pellets containing tamsulosin hydrochloride. Arch. Pharm. Res., v.30, n.8, p.1008-1013, 2007.

LAI, S.K.; WANG, Y.-Y.; HANES, J. Mucus-penetrating nanoparticles for drug and gene delivery to mucosal tissues. Adv. Drug Deliver. Rev., v.61, n.2, p.158-171, 2009.

LING, G.; ZHANG, P.; ZHANG, W.; SUN, J.; MENG, X.; QIN, Y.; DENG, Y.; HE, Z. Development of novel selfassembled DS-PLGA hybrid nanoparticles for improving oral bioavailability of vincristine sulfate by P-gp inhibition. J. Control. Release, v.148, n.2, p.241-248, 2010.
MAKHLOF, A.; TOZUKA, Y.; TAKEUCHI, H. Design and evaluation of novel $\mathrm{pH}$-sensitive chitosan nanoparticles for oral insulin delivery. Eur. J. Pharm. Sci., v.42, n.5, p.445-451, 2011.

MARU, S.M.; DE MATAS, M.; KELLY, A.; PARADKAR, A. Characterization of thermal and rheological properties of zidovidine, lamivudine and plasticizer blends with ethyl cellulose to assess their suitability for hot melt extrusion. Eur. J. Pharm. Sci., v.44, n.4, p.471-478, 2011.

MIYAZAKI, T.; ASO, Y.; YOSHIOKA, S.; KAWANISHI, T. Differences in crystallization rate of nitrendipine enantiomers in amorphous solid dispersions with HPMC and HPMCP. Int. J. Pharm., v.407, n.1-2, p.111-118, 2011.

MUDRA, D.R.; BORCHARDT, R.T. Absorption barriers in the rat intestinal mucosa. 3: Effects of polyethoxylated solubilizing agents on drug permeation and metabolism. $J$. Pharm. Sci., v.99, n.2, p.1016-1027, 2010.

OLIVEIRA, G.F.; FERRARI, P.C.; CARVALHO, L.Q.; EVANGELISTA, R.C. Chitosan-pectin multiparticulate systems associated with enteric polymers for colonic drug delivery. Carbohydr. Polym., v.82, n.3, p.1004-1009, 2010.

PREZOTTI, F.G.; MENEGUIN, A.B.; EVANGELISTA, R.C.; CURY, B.S.F. Preparation and characterization of free films of high amylose/pectin mixtures cross-linked with sodium trimetaphosphate. Drug Dev. Ind. Pharm., v.38, n.11, p.1-6, 2012.

PUTTIPIPATKHACHORN, S.; PONGJANYAKUL, T.; PRIPREM, A. Molecular interaction in alginate beads reinforced with sodium starch glycolate or magnesium aluminum silicate, and their physical characteristics. Int. J. Pharm., v.293, n.1-2, p.51-62, 2005.

QUEVEDO, M.A.; NIETO, L.E.; BRIÑÓN, M.C.P-glycoprotein limits the absorption of the anti-HIV drug zidovudine through rat intestinal segments. Eur. J. Pharm. Sci., v.43, n.3, p.151-159, 2011.

REPKA, M.A.; MCGINITY, J.W. Physical - mechanical, moisture absorption and bioadhesive properties of hydroxypropylcellulose hot-melt extruded films. Biomaterials, v.21, n.14, p.1509-1517, 2000. 
REPKA, M.A.; MCGINITY, J.W. Bioadhesive properties of hydroxypropylcellulose topical films produced by hot-melt extrusion. J. Control. Release, v.70, n.3, p.341-351, 2001.

SHEN, Q.; LIN, Y.; HANDA, T.; DOI, M.; SUGIE, M.; WAKAYAMA, K.; OKADA, N.; FUJITA, T.; YAMAMOTO, A. Modulation of intestinal P-glycoprotein function by polyethylene glycols and their derivatives by in vitro transport and in situ absorption studies. Int. J. Pharm., v.313, n.1-2, p.49-56, 2006.

SOARES, G.A.; CASTRO, A.D.D.; CURY, B.S.F.; EVANGELISTA, R.C. Blends of cross-linked high amylose starch/pectin loaded with diclofenac. Carbohydr. Polym., v.91, n.1, p.135-142, 2013.

TAKIZAWA, Y.; KISHIMOTO, H.; NAKAGAWA, M.; SAKAMOTO, N.; TOBE, Y.; FURUYA, T.; TOMITA, M.; HAYASHI, M. Effects of pharmaceutical excipients on membrane permeability in rat small intestine. Int. J. Pharm., v.453, n.2, p.363-370, 2013.
TEIXEIRA, C.; GOMES, J.R.B.; GOMES, P.; MAUREL, F. Viral surface glycoproteins, gp120 and gp41, as potential drug targets against HIV-1: Brief overview one quarter of a century past the approval of zidovudine, the first antiretroviral drug. Eur. J. Med. Chem., v.46, n.4, p.979-992, 2011.

VARATHARAJAN, L.; THOMAS, S.A. The transport of anti-HIV drugs across blood-CNS interfaces: summary of current knowledge and recommendations for further research. Antivir. Res., v.84, n.2, p.10, 2009.

WERLE, M. Natural and synthetic polymers as inhibitors of drug efflux pumps. Pharm. Res., v.25, n.3, p.500-511, 2008.

Received for publication on $30^{\text {th }}$ September 2015 Accepted for publication on $25^{\text {th }}$ August 2016 
